\title{
Anticonvulsant Effects of Trigonella foenum-Graecum $L$. in Strychnine Induced Epilepsy Model
}

\author{
Tahira Assad ${ }^{1}$, Rafeeq Alam Khan ${ }^{* 2}$ and Muhammad Ali Rajput ${ }^{3}$ \\ ${ }^{1}$ Department of Pharmacology, Karachi Institute of Medical Sciences, CMH, Malir Cantt, Karachi \\ ${ }^{2}$ Department of Pharmacology, Faculty of Pharmacy and Pharmaceutical Sciences, University of Karachi, Karachi-75270
}

${ }^{3}$ Department of Pharmacology, Multan Medical and Dental College, Multan, Karachi

Received: November 8, 2017; Accepted: November 24, 2017; Published: : December 4, 2017

*Corresponding author: Rafeeq A Khan, Department of Pharmacology, Faculty of Pharmacy and Pharmaceutical Sciences, University of Karachi, Karachi-75270; E-mail: rkhan1959@gmail.com

\begin{abstract}
Background: Epilepsy is the 2nd greatest prevalent brain ailment after stroke, and a huge load on health system. Currently available antiepileptic drugs are associated with a lot of adverse effects and exhibit erratic pharmacological effects; hence it is crucial to explore newer anticonvulsant medications having better side effect profile and enhanced pharmacological effects because of the lengthy duration of treatment of epilepsy. Plants are rich source of various bioactive compounds. Numerous plants have been authenticated to be the source of safe and effective medicines and served as substitute to modern medicine.
\end{abstract}

Method: In this study, anticonvulsant action of Trigonella foenumgraecum $L$. was evaluated in rats by strychnine induced convulsions at three different doses after 14 days of continuous administration. Diazepam at $1 \mathrm{mg} / \mathrm{kg}$ was consumed as a standard drug. The time to onset of first convulsion, number of convulsions, and duration of convulsions, mortality rate and percent protection was recorded for each animal. Present study was specifically designed to evaluate the anticonvulsant effects of T. foenum-graecum $L$. Seeds methanol extract.

Result: Administration of TFGS-ME for 14 days to rats exhibited significant delay in onset of convulsion at 50 and $100 \mathrm{mg} / \mathrm{kg}$ while highly significant delay at $200 \mathrm{mg} / \mathrm{kg}$ comparable to diazepam. Frequency of convulsion was also decreased significantly at 100 and $200 \mathrm{mg} / \mathrm{kg}$, comparable to diazepam. Duration of convulsion was also decreased significantly at all the three doses given in comparison to control animals. Percent protection in animals received TFGS-ME at $200 \mathrm{mg} / \mathrm{kg}$ was $90 \%$ within $24 \mathrm{~h}$ as compared to $10 \%$ protection in control animals.

Conclusion: Present study gives enough evidences regarding the potential of T. foenum-graecum $L$. as anticonvulsant agent.

Key words: Anticonvulsant; Trigonella foenum-graecum L.; strychnine induced convulsions

\section{Introduction}

Epilepsy is one of the frequently occurring neurological illnesses, characterized by recurring seizures with or without loss of consciousness, due to abnormal discharge of cerebral neurons. It has a universal occurrence of $0.5-5 \%$ [1].

It is a chronic progressive disease and affects quality of life [2]. The incidence of epilepsy in industrialized states is about 50 per 100,000 whereas in emerging undeveloped states, it is 100 per 100,000 affecting individuals of all ages, races, and social groups [3]. Epilepsy has many possible causes such as infection, head trauma, brain malignancy and stroke. A variety of drugs including, antipsychotics antidepressants, levodopa, thiazide diuretics and antibiotics, can also increase the frequency of seizures [4].

It is suggested that there is an imbalance between GABA and glutamate-mediated neurotransmission in the pathogenesis of epilepsy. Low catecholamine levels can be another causative factor of epilepsy $[5,6,7]$.

The pathophysiology of the seizure disorder is complex. It may result from permanent modifications in the brain affecting neurotransmitters discharge and movement, receptors and ion channels, gene expressions, synapses and astrocytes. Initially, it was considered that modifications in ion channels may cause the onset of the involuntary depolarization that begins seizures. Current researches propose that numerous neuro chemical conduits contribute significantly in seizure onset and progression [8].

Epilepsy is not treatable, but can be managed with anticonvulsant drugs which either prevent the initiation of convulsions or decrease the intensity of seizures [9]. Around, $70 \%$ of sufferers of epilepsy show better outcome on single drug therapy by currently available medicines. While $5-10 \%$ of patients are benefited by adding a second drug. Remaining 20 percent of patients are resistant to the treatment [10].Therefore, there is need to develop a better anticonvulsant drug [11].

Anticonvulsant drugs of first generation have propensity for drug-drug interactions and side effects due to enzyme induction 
or inhibition [12]. Adverse effects of the antiepileptic drugs may affect the patient's quality of life to a greater extent than the epilepsy itself which is a challenging situation for a physician [13].

Natural products are potential basis of bioactive substances and are used worldwide as traditional medicinal remedies. Many of the synthetic drugs are derived from plant sources $[14,15]$. Therapeutic plants identified to have anticonvulsant activity in animal models include: Abelmoschus angulosus, Allium sativum, Cinchona officinalis, Egletes viscosa, Cannabis sativa, Icacina trichantha, Magnolia grandiflora, Plumbago zeylanica, Artemisia spp, Bauhinia outimouta, Rauvolfia ligustrina and Ximenia Americana [16].

Trigonella foenum-graecum Linn. (Fenugreek) is a wellidentified old medicinal plant belonging to the family Fabaceae, various parts of which are consumed as food constituent such as leaves and seeds [17].

This study was executed consuming seeds of $T$. foenumgraecum $L$. Seeds are small (3-5 mm long, $2 \mathrm{~mm}$ thick) having hard texture, fluctuating from yellowish brown to brown in color. They are flattened and have a distinctive rhomboid shape. They have a distinguished peppery odor, bitter and mucilaginous taste [18].

Seeds are conventionally used as spice in our food. Prehistoric people used it customarily for various medicinal uses. It is a rich source of various bioactive compounds such as saponins (fenugreekine, diosgenin), alkaloids (trigonelline, gentianine, carpaine), amino acids (4-Hydroxy isoleucin, arginine) and flavonoids [19, 20]. Literature review showed numerous scientifically assessed activities such as hypoglycemic, Raju, et al. hypolipidemic, antioxidant, anticancer and antiulcer activities [21-25].

Present study was especially designed to evaluate anticonvulsants effects T.foenum-graecum L. seeds methanol extract (TFGS-ME) in strychnine induced epilepsy model.

\section{Materials and Methods}

\section{Formulation of extract}

Cold extraction method was executed to formulate crude extract of methanol [26]. Seeds were purified from all scums manually and crushed to obtain fine powder, which was immersed in $80 \% 1000 \mathrm{ml}$ methanol for 10 days in air tight jars with their caps tightly closed. Jars were shaken frequently every 2 days until the solvent turn out to be medium brown in color. The acquired solvent was sieved first through cotton and then by What-mann No.1 filters paper. Subsequently the obtained filtrate was vaporized under reduced pressure by means of a rotary evaporator at $45^{\circ} \mathrm{C}$, followed by freeze drying at $-30^{\circ} \mathrm{C}$ of temperature. The crude extract of methanol so developed was preserved in petri dishes and kept at $-20^{\circ} \mathrm{C}$ of temperature.

\section{Animals}

This study was conducted at Department of Pharmacology, Faculty of Pharmacy and Pharmaceutical Sciences, University of Karachi after the approval by Board of Advanced Studies and Research (BASR) of University of Karachi. Albino rats of either gender weighing in the range of 180-220 g were procured from Hussain Ebrahim Jamal (HEJ) Research Institute of Chemistry, University of Karachi. All animals were retained in plastic cages placed at the animal house of Department of Pharmacology, University of Karachi, under strict condition soft temperature (22 $\pm 2^{\circ} \mathrm{C}$ ) and humidity (50-60\%) in an alternating 12-h light/dark cycle. Animals were fed with standard food and water regularly. Guidelines of National Institute of Health (NIH) were followed for handling and experimentation on animals [27].

\section{Grouping and Dosing}

50 albino rats of either gender weighing around 180-220 g were randomly divided into five groups, each having 10 animals. One group was tagged as control and given distilled water $1 \mathrm{ml} /$ $\mathrm{kg}$ body weight orally once a day. Second group was marked as standard and given diazepam (Karachi Pharmaceutical Laboratories) in the dose of $1 \mathrm{mg} / \mathrm{kg}$ orally once a day. Diazepam tablet was crushed to fine powder and suspended in distilled water, which was administered orally using orogastric tube [28]. Three test groups received TFGS-ME in three different doses i.e. $50 \mathrm{mg}, 100 \mathrm{mg}$, and $200 \mathrm{mg} / \mathrm{kg}$ body weight dissolved in $1 \mathrm{ml}$ distilled water orally once a day. All the treatments were administered continuously for 14 days.

\section{Testing}

Strychnine (Sigma-Aldrich Inc., St. Louis, MO, USA) was used to induce convulsions in animals.

\section{Strychnine Induced Convulsions}

\section{Procedure}

After the completion of dosing on day 14, approximately 40 minutes after the last treatment, strychnine was injected to animals of all groups for inducing convulsions through intraperitoneal route in the dose of $4 \mathrm{mg} / \mathrm{kg}$ after dissolving in distilled water. Animals in which convulsions were not induced after injecting strychnine were separated as safe. The time to onset of convulsions, duration of convulsions, number of convulsions during $1 \mathrm{~min}$ duration, mortality rate and percent protection was recorded for each animal [29]. Strychnine antagonizes the inhibitory reflexes from brain and spinal cord as well as augments reflexes from spinal cord, therefore induced convulsions [30].

\section{Statistics}

Data was analyzed using Superior Performance Statistical Software (SPSS) version 23, and is presented as mean \pm SEM with $95 \%$ confidence interval. Anova trailed by post hoc was accomplished for comparisons of values with control. Values of $\mathrm{P}<0.05$ were considered significant and $P<0.001$ as highly significant. 


\section{Results}

Table 1 demonstrates the effect of TFGS-ME and diazepam on strychnine induced convulsions in rats after 14 days of uninterrupted administration. The time to onset of first convulsion, number of convulsions and duration of convulsion were recorded.

The onset of first convulsion in TFGS-ME I and TFGS-ME II groups which received extract at 50 and $100 \mathrm{mg} / \mathrm{kg}$ body weight respectively was delayed significantly i.e. $190.36+33.00 \mathrm{~s}$ and $187.36+41.13$ s respectively in contrast to control animals i.e. $119.47+39.55 \mathrm{~s}$, while the onset of first convulsion in TFGS-ME III group which received extract at $200 \mathrm{mg} / \mathrm{kg}$ body weight and animals which received standard drug diazepam at $1 \mathrm{mg} / \mathrm{kg}$ body weight was delayed highly significantly i.e. $389.14+23.4 \mathrm{~s}$ and $302.17+24.1 \mathrm{~s}$ respectively in contrast to control animals.
The effect on number of convulsions in TFGS-MEI group which received extract at $50 \mathrm{mg} / \mathrm{kg}$ body weight was statistically inconsequential i.e. $3.00+0.14$ in contrast to the control animals i.e. $3.00+0.77$. The number of convulsions in TFGS-ME II, TFGSME III groups which received extract at 100 and $200 \mathrm{mg} / \mathrm{kg}$ body weight respectively and in animals received standard drug diazepam at $1 \mathrm{mg} / \mathrm{kg}$ body weight were reduced significantly i.e. $1.00+0.31,1.00+0.19$ and $1.00+0.61$ respectively in contrast to control animals.

The duration of convulsions in TFGS-ME I, TFGS-ME II, TFGSME III groups which received extract at 50,100 and $200 \mathrm{mg} / \mathrm{kg}$ body weight respectively and animals received standard drug diazepam at $1 \mathrm{mg} / \mathrm{kg}$ body weight were reduced significantly i.e. $24.31+1.55 \mathrm{~s}, 21.57+1.03 \mathrm{~s}, 19.71+2.49 \mathrm{~s}$ and $16.99+1.86 \mathrm{~s}$ respectively.

Table 1: Effect of TFGS-ME and Diazepam on Strychnine induced Convulsions

\begin{tabular}{|c|c|c|c|}
\hline Group/Dosage & Onset of Convulsions (sec) & No. of Convulsions (1 min) & Duration of Convulsions (sec) \\
\hline Distilled Water $1 \mathrm{ml} / \mathrm{kg}$ & $119.47+39.55$ & $3.00+0.77$ & $39.29+1.79$ \\
\hline Diazepam 1mg/kg & $302.17+24.1^{* *}$ & $1.00+0.61^{*}$ & $16.99+1.86^{*}$ \\
\hline TFGS-ME I $50 \mathrm{mg} / \mathrm{kg}$ & $190.36+33.00^{*}$ & $3.00+0.14$ & $24.31+1.55^{*}$ \\
\hline TFGS-ME II $100 \mathrm{mg} / \mathrm{kg}$ & $187.36+41.13^{*}$ & $1.00+0.31^{*}$ & $21.57+1.03^{*}$ \\
\hline TFGS-ME III 200mg/kg & $389.14+23.4^{* *}$ & $1.00+0.19^{*}$ & $19.71+2.49^{*}$ \\
\hline \multicolumn{4}{|c|}{$\begin{array}{l}\mathrm{n}=10 \text { values are stated as mean } \pm \text { standard error of mean } \\
{ }^{*} \mathrm{P} \leq 0.05 \text { noteworthy in contrast to control } \\
{ }^{* *} \mathrm{P} \leq 0.001 \text { highly noteworthy in contrast to control group } \\
\mathrm{TFGS}-\mathrm{ME}=\text { Trigonella foenum-graecum Seeds-Methanol Extract }\end{array}$} \\
\hline
\end{tabular}

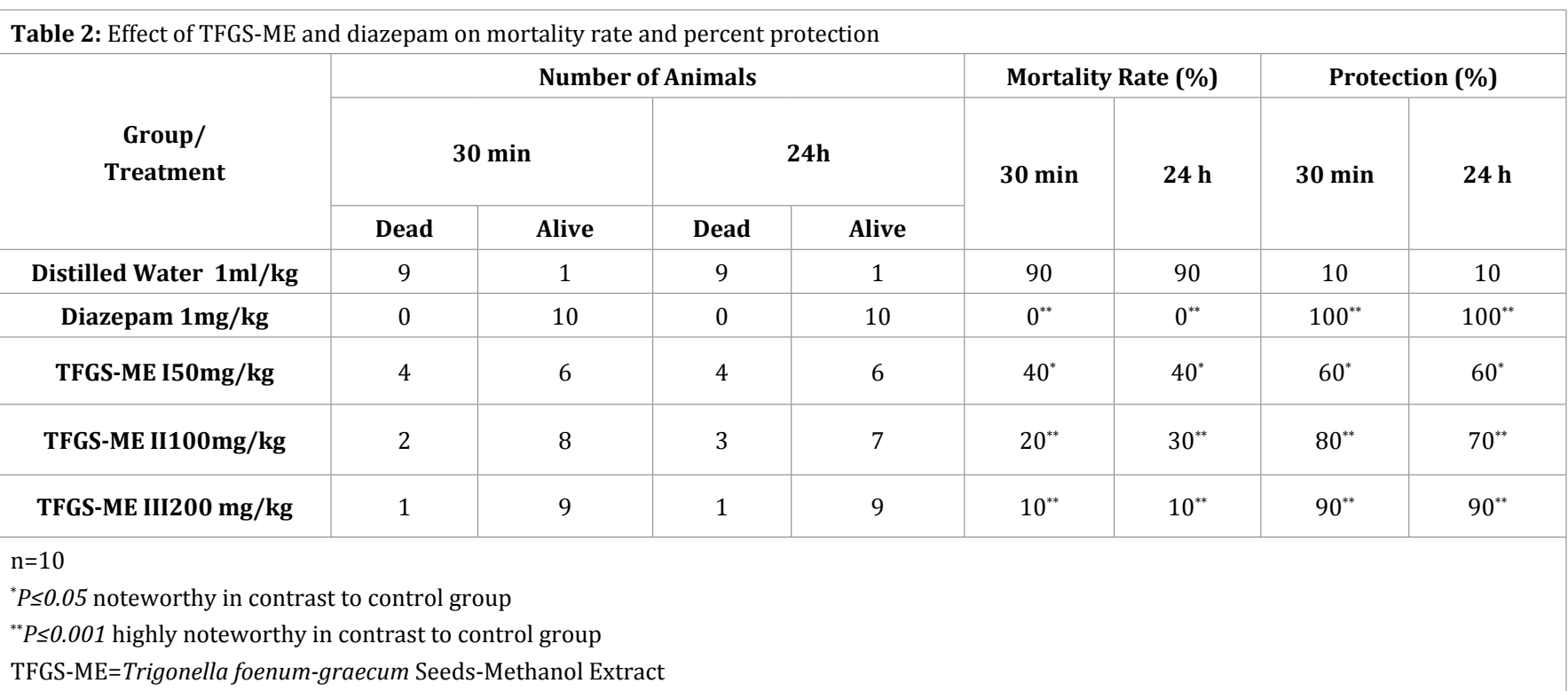

Table 2 demonstrates the effect of TFGS-ME and diazepam on mortality rate and percent protection in Strychnine induced convulsions after 14 days of uninterrupted administration to animals.
The mortality rate in TFGS-ME I group which received $50 \mathrm{mg} /$ $\mathrm{kg}$ extract was $40 \%$ at $30 \mathrm{~min}$ and after $24 \mathrm{~h}$ in contrast to the control animals which was $90 \%$. Hence it revealed 60 percent protection in contrast to $10 \%$ in control animals. The mortality 
rate in TFGS-ME II group which received $100 \mathrm{mg} / \mathrm{kg}$ extract was $20 \%$ at $30 \mathrm{~min}$ and $30 \%$ after $24 \mathrm{~h}$ in contrast to control animals. Hence it revealed 80 percent protection at $30 \mathrm{~min}$ and $70 \%$ protection after $24 \mathrm{~h}$ in contrast to control animals. The mortality rate in TFGS-ME III group which received $200 \mathrm{mg} / \mathrm{kg}$ extract was $10 \%$ at $30 \mathrm{~min}$ and after $24 \mathrm{~h}$ in contrast control animals which was $90 \%$. Hence it revealed 90 percent protection in contrast to $10 \%$ protection in control animals. However mortality rate in animals received standard drug diazepam was $0 \%$ both at $30 \mathrm{~min}$ and after $24 \mathrm{~h}$ in contrast to control animals, hence revealed 100 percent protection in contrast to control animals.

\section{Discussion}

Traditional medicine represents health systems, methods and principles encompassing plants, animals and minerals derived medications, spiritual treatments and biological methods, used alone or in combination to diagnose, cure and prevent the ailment. The world marketplace for herbal remedies currently occupies over US $\$ 60$ billion per annum and is developing gradually [31].

Epilepsy is the 2nd greatest prevalent brain ailment after stroke, and a huge load on health system. Currently available antiepileptic drugs are associated with a lot of adverse effects and erratic pharmacological effects; hence it is crucial to explore newer anticonvulsant medications having better side effect profile and enhanced pharmacological effects as the treatment of epilepsy is for extensive duration. Traditional herbal medicines are safer to use because of their moderate degree of bio reactivity. Researchers are trying to separate and distinguish the bioactive compounds of the medicinal plants which can be utilized in new drug developments [32-35].

In the present investigation, anticonvulsant action of TFGSME was evaluated in rats by strychnine induced convulsions at three different doses after 14 days of continuous administration. Diazepam at $1 \mathrm{mg} / \mathrm{kg}$ was consumed as a standard drug. The time to onset of first convulsion, number of convulsions, duration of convulsions, mortality rate and percent protection was recorded.

Strychnine produces convulsions by interfering the postsynaptic inhibition facilitated by glycine which is an inhibitory neurotransmitter to the spinal cord neurons. Strychnine actions as a selective competitive antagonist to prevent the inhibitory actions of glycine at the receptors. Researches recommend that strychnine and glycine act at the same receptor but at varying positions. The levels of the amino acid glutamic acid are also increased in brain, which acts as a neurotransmitter for excitatory nerve impulses leading to myocontraction [36].

Administration of TFGS-ME for 14 days to rats revealed significant delay in onset of convulsion at 50 and $100 \mathrm{mg} / \mathrm{kg}$ while highly significant delay at $200 \mathrm{mg} / \mathrm{kg}$ and comparable to diazepam. Frequency of convulsion was also decreased highly significantly at 100 and $200 \mathrm{mg} / \mathrm{kg}$, which were comparable to diazepam Duration of convulsion was also decreased significantly at all the three doses given in comparison to control animals.. Percent protection in animals received TFGS-ME at $200 \mathrm{mg} / \mathrm{kg}$ was $90 \%$ within $24 \mathrm{~h}$ as compared to $10 \%$ protection in control animals.

It is recognized that some flavonoids and their glycosides possess anticonvulsant effects. More than 5000 types of flavonoids have been isolated, and the pharmacological features of many of them have been identified. Many flavonoids exert anticonvulsant action by modifying the GABAA-Cl-channel composite because of their structural similarity to benzodiazepines [37-39].

Vitexin, quercetin, isoquercitrin, and rutin type of flavonoids, exhibited anticonvulsant effects in investigational epilepsy models. Vitexin is a C-glycosylated type of flavone present in numerous plants. It exerts anticonvulsant effects by augmenting the duration of seizure onset in PTZ-induced seizures in animals, probably through binding at the benzodiazepine site of the GABAA receptor complex. Quercetin also showed anticonvulsant effects. It is suggested that it modulates GABAA receptors and antagonizes N-methyl D aspartate (NMDA) receptors. Rutin revealed anticonvulsant effect in kainic acid induced seizures by decreasing oxidative stress. Moreover, rutin acts as a ligand for benzodiazepine receptors through positive allosteric modulation of the GABAA receptor. Anticonvulsant action of TFGS-ME can be ascribed to presence of various flavonoids in it [39-44].

Seizures weaken the antioxidant defense mechanism of brain leading to free radicals generation, which further provokes the oxidative stress and cause lipid peroxidation, brain edema and epilepsy. Moreover free radicals by inactivating the enzyme glutamine synthase increase the production of excitatory neurotransmitter glutamic acid, resulting in seizure induction. This is correlated with a decrease in the brain GABA levels by inhibiting the enzyme glutamate decarboxylase by free radicals $[2,45,46]$. It is safe to conclude that anticonvulsant action of TFGS-ME could be due to its antioxidant effect [23].

Various other phytochemicals are also reported to possess anticonvulsant activity such as luteolin depicted anticonvulsant effect in an acute pentylenetetrazole induced seizure model. Gentian in revealed anticonvulsant effect by affecting the cytokines regulating hypothalamic prostaglandin E2 (PGE2) levels. Diosgenin significantly prevented seizures in PTZ induced kindling model. T. foenum-graecum L. seeds contain luteolin, gentianine and diosgenin phytochemicals, favoring its anticonvulsant potential $[19,35,44,47,48]$.

\section{Conclusion}

Present study gives several clues regarding the potential of T. foenum-graecum $L$. as anticonvulsant agent. Hence there is extreme necessity to isolate the dietary constituents which may play a dynamic role in future invention of novel drugs.

\section{Acknowledgement}

Authors are thankful to Dr. Muhammad Mohtashim, Associate Professor Department of Pharmacognosy, for identifying fenugreek seeds and chairperson Department of Pharmacology, University of Karachi for providing technical and financial help to complete this piece of work. 


\section{References}

1. Goldenberg MM. Overview of drugs used for epilepsy and seizures: etiology, diagnosis, and treatment. Pharm Ther. 2010;35(7):392-415.

2. Ramalingam R, Nath AR, Madhavi BB, Nagulu M, Balasubramaniam A. Free radical scavenging and antiepileptic activity of Leucas lanata. J Pharm Res. 2013;6(3):368-372.

3. Gupta G, Dua K, Kazmi I, Anwar F. Anticonvulsant activity of Morusin isolated from Morusalba: Modulation of GABA receptor. Biomed Aging Pathol. 2014;4(1):29-32.

4. Franson KL, Hay DP, Neppe V, Dahdal WY, Mirza WU, Grossberg GT, et al. Drug-induced seizures in the elderly. Causative agents and optimal management. Drugs aging. 1995;7(1):38-48.

5. de Almeida RN, de Sousa DP, de Farias Nóbrega FF, de Sousa CF, Araújo DAM, Leite J R,Mattei R. Anticonvulsant effect of a natural compound $\alpha, \beta$-epoxy-carvone and its action on the nerve excitability. Neurosci. Lett. 2008;443(1):51-55. doi: 10.1016/j.neulet.2008.07.037

6. Grosso C, Valentão P, Ferreres F, Andrade PB. The use of flavonoids in central nervous system disorders. Curr Med Chem. 2013;20(37):46944719.

7. Shrestha S, Park JH, Lee DY, Cho JG, Cho S, Yang HJ, et al. Rhusparviflora and its bioflavonoid constituent, rhusflavone, induce sleep through the positive allosteric modulation of $\operatorname{GABA}(\mathrm{A})$-benzodiazepine receptors. J Ethnopharmacol. 2012;142(1):213-220. doi: 10.1016/j. jep.2012.04.047

8. Kumar S, Madaan, R, Bansal G, Jamwal A, Sharma A. Plants and plant products with potential anticonvulsant activity-A review. PhcogCommn. 2012;2(1):3-99.

9. Adams M, Schneider SV, Kluge M, Kessler M, Hamburger M. Epilepsy in the Renaissance: a survey of remedies from 16 th and 17 th century German herbals. J Ethnopharmacol. 2012;143(1):1-13. doi: 10.1016/j. jep.2012.06.010

10. Richens A, Perucca E. In General principles in drug treatment of epilepsy. Textbook of epilepsy. 4 th ed. Edinburgh. Churchill Livingstone Communications, 1993.

11. Nsour WM, Lau CB, Wong ICK. Review on Phytotherapy in epilepsy. Seizure. 2000;9(2):96-107. DOI: 10.1053/seiz.1999.0378

12. Stefan H, da Silva FHL. Epileptic neuronal networks: methods of identification and clinical relevance. Front Neurol. 2013;4:8. doi: 10.3389/fneur.2013.00008

13. Eatock J, Baker GA. Managing patient adherence and quality of life in epilepsy. Neuropsychi Dis Treat. 2007;3(1):117-131.

14. Katiyar C, Gupta A, Kanjilal S, Katiyar S. Drug discovery from plant sources: An integrated approach. Ayu. 2012;33(1):10-19. doi: 10.4103/0974-8520.100295

15. Howes MJR, Houghton PJ. Traditional medicine for memory enhancement. In: Ramawat KG (ed) Herbal drugs: Ethnomedicine to modern medicine. Springer, Berlin, 2009.

16. Quintans-Júnior LJ, Almeida JRGS, Lima JT, Nunes XP, Siqueira JS, Oliveira LEG. Plants with anticonvulsant properties: a review. Rev. Bras. Farmacogn. 2008;18:798-819.

17. Nathiya S, Durga M, Devasena T. Therapeutic role of Trigonella foenum-graecum [Fenugreek]-a review. Int. J. Pharm. Sci. Rev. Res. 2014;27(2):74-80.
18. Didarshetaban MB, Pour S, Reza H. Fenugreek (Trigonella foenumgraecumL.) as a valuable medicinal plant. Inter J Adv Biol Biom Res. 2013;1(8): 922-931.

19. Kan Y, Kan A, Ceyhan T, Sayar E, Kartal M, Altun L, et al. Atomic absorption spectrometric analysis of Trigonella foenum-graecum $L$. seeds cultivated in Turkey. Turkish J Pharm Sci. 2005;2(3):187-191.

20. Patil S, Jain G. Holistic approach of Trigonella foenum-graecum in Phytochemistry and Pharmacology. Curr Trends in Technol Sci. 2014;3(1):34.

21. RajuJ,GuptaD, Rao AR, Yadava PK, Baquer NZ. Trigonellafoenumgraecum (fenugreek) seed powder improves glucose homeostasis in alloxan diabetic rat tissues by reversing the altered glycolytic, gluconeogenic and lipogenic enzymes. Mol Cell Biochem. 2001;224(1):45-51.

22. Ribes G, Da Costa C, Loubatières-Mariani MM, Sauvaire Y, Baccou JC. Hypocholesterolemic and hypo-triglyceridemic effects of subfractions from fenugreek seeds in alloxan diabetic dogs. Phytother Res, 1987;1(1):38-43.

23. Rababah TM, Hettiarachchy NS, Horax R. Total phenolics and antioxidant activities of fenugreek, green tea, black tea, grape seed, ginger, rosemary, gotu kola, and ginkgo extracts, vitamin $\mathrm{E}$, and tertbutylhydroquinone. J Agric Food Chem. 2004;52(16):5183-5186. DOI: $10.1021 /$ jf049645z

24. Shabbeer S, Sobolewski M, Anchoori RK, Kachhap S, Hidalgo M, Jimeno A, et al. Fenugreek: a naturally occurring edible spice as an anticancer agent. Cancer Biol Ther. 2009;8(3):272-278.

25. Kaur J, Singh H, Khan MU. Multifarious therapeutic potential of fenugreek: a comprehensive review. Int J Res Pharm Biomed Sci. 2011;2(3):863-871.

26. Hossain MS, Ahmed M, Islam A. Hypolipidemic and hepatoprotective effects of different fractions of ethanolic extract of immature leaves of Mangiferaindica (Linn.) in alloxan induced diabetic rats. Int J Pharm Sci Res. 2010;1(11):132-138.

27. National Research Council. Guide for the care and use of laboratory animals. Institute of Laboratory Animal Resources, Commission on Life Sciences. National Academy of Sciences, Washington.1996.

28. Martinez AL, Dominguez F, Orozco S, Chavez M, Salgado H, GonzalezTrunjano ME. Neuropharmacological effects of an ethanol extract of the Magnolia dealbatazucc. Leaves in mice. J Ethnopharmacol. 2006;106(2):250-255.

29. Rasilingam D, Duraisamy S, Subramanian R. Anticonvulsant activity of bioflavonoid gossypin. Bangladesh J Pharmacol. 2009;4(1):51-54.

30. Biggio G, Cibin M, Diana M, Fadda F, Ferrara SD, Gallimberti L, et al. Suppression of voluntary ethanol intake in rats and alcoholics by gamma-hydroxybutyric acid: a non-GABAergic mechanism. Adv Biochem Psycho pharmacol. 1992;47:281-288.

31. World Health Organization. Traditional medicine. 2003.

32. Madhu A, Keerthi PHV, Singh J, Shivalinge GKP. To evaluate the antiepileptic activity of aqueous root extract of HemidesmusIndicus in rats. Arch Pharm Sci Res. 2009;1(1):43-47.

33. Roger JP, Brian SM. Antiepileptic drug In: Katzung BG. Basic and Clinical Pharmacology. 1996.

34. Elvin-Lewis, M. Should we be concerned about herbal remedies. J Ethnopharmacol. 2001;75(2-3):141-164. 
35. Liu YF, Gao F, Li XW, Jia RH, Meng XD, Zhao R, et al. The anticonvulsant and neuroprotective effects of baicalin on pilocarpine-induced epileptic model in rats. Neurochem Res. 2012;37(8):1670-1680. doi: 10.1007/s11064-012-0771-8

36. Ramesh CG. Skeletal muscle toxicity biomarkers. Biomarkers in Toxicology. Elsevier. 2014.

37. Estrada-Reyes R, Martínez-Vázquez M, Gallegos-Solís A, Heinze G, Moreno J. Depressant effects of ClinopodiummexicanumBenth. Govaerts (Lamiaceae) on the central nervous system.JEthnopharmacol 2010;130(1):1-8. doi: 10.1016/j.jep.2010.03.012

38. Du XM, Sun NY, Takizawa N, Guo YT, Shoyama Y. Sedative and anticonvulsant activities of goodyerin, a flavonol glycoside from Goodyeraschlechtendaliana. Phytother Res. 2002;16(3):261-263.

39. Choudhary N, Bijjem KRV, Kalia AN. Antiepileptic potential of flavonoids fraction from the leaves of Anisomelesmalabarica. J Ethnopharmacol. 2011;135(2):238-242.

40. Orhan N, Orhan DD, Aslan M, Şüküroğlu M, Orhan IE. UPLC-TOFMS analysis of Galiumspurium towards its neuroprotective and anticonvulsant activities. J Ethnopharmacol. 2012;141(1):220-227. doi: 10.1016/j.jep.2012.01.056

41. Abbasi E, Nassiri-Asl M, Shafeei M, Sheikhi M. Neuroprotective Effects of Vitexin, a Flavonoid, on Pentylenetetrazole-Induced Seizure in Rats. ChemBiol Drug Des. 2012;80(2):274-278. doi: 10.1111/j.17470285.2012.01400.x

42. Nassiri-Asl M, Naserpour-Farivar T, Abbasi E, Sadhegnia HR, Sheikhi $\mathrm{M}$, Lotfizadeh M, et al. Effects of rutin on oxidative stress in mice with kainic acid-induced seizure. J integr Med. 2013;11(5):337-342. doi 10.3736/jintegrmed2013042
43. Nassiri-Asl M, Shariati-Rad S, Zamansoltani F. Anticonvulsive effects of intracerebroventricular administration of rutin in rats. ProgNeuropsychopharmacolBiol Psychiatry. 2008;32(4):989-993. doi: 10.1016/j.pnpbp.2008.01.011

44. Rayyan S, Fossen T, Andersen OM. Flavone C-glycosides from seeds of fenugreek, Trigonellafoenum-graecum L. J Agric Food Chem. 2010;58(12):7211-7217. doi: 10.1021/jf100848c

45. Cardenas-Rodriguez N, Huerta-Gertrudis B, Rivera-Espinosa L, Montesinos-Correa H, Bandala C, Carmona-Aparicio L, et al. Role of oxidative stress in refractory epilepsy: evidence in patients and experimental models. IntJ Mol Sci. 2013;14(1):1455-1476. doi: 10.3390/ijms14011455

46. Naziroğlu M, Akay MB, Çelik Ö, Yildirim MI, Balci E, Yürekli VA. Capparisovata modulates brain oxidative toxicity and epileptic seizures in pentylenetetrazole induced epileptic rats. Neurochem Res. 2013;38(4):780-788. doi: 10.1007/s11064-013-0978-3

47. Tambe R, Patil A, Jain P, Sancheti J, Somani G, Sathaye S. Assessment of luteolin isolated from Eclipta alba leaves in animal models of epilepsy. Pharm Biol. 2017;55(1):264-268. DOI: 10.1080/13880209.2016.1260597

48. Shakuntala S, Naik JP, Jeyarani T, Naidu MM, Srinivas P. Characterisation of germinated fenugreek (Trigonellafoenum-graecum $L$.) seed fractions. Int J Food Sci Tech. 2011;46(11):2337-2343. DOI: 10.1111/j.13652621.2011.02754.x 